\title{
Thyrotoxic Vomiting: A Case Report and Possible Mechanisms
}

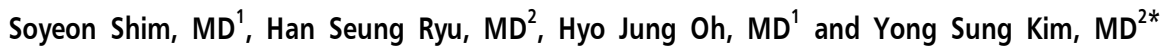 \\ ${ }^{1}$ Department of Internal Medicine, Wonkwang University Sanbon Hospital, Gunpo, Gyeonggi-do, ${ }^{2}$ Digestive Disease Research Institute, \\ Wonkwang University School of Medicine, Iksan, Jeollabuk-do, Korea
}

The symptoms related to gastrointestinal (GI) tract are sometimes chief complaints in patients with endocrine disease. Thyrotoxicosis is a rare, but notable cause for unexplained and repeated vomiting. Here, we report an adolescent patient with thyrotoxicosis who was initially presented with repeated vomiting and epigastric pain. A 13-year-old female was referred to a Gl outpatient department for evaluation of vomiting and abdominal pain from a pediatric clinic. Esophagogastroduodenoscopy revealed acute gastritis with duodenogastric reflux and suspicious reflux esophagitis of minimal change, but there was no significant improvement after treatment and as a result she was admitted to the emergency room. She was subsequently diagnosed as Graves' disease because an initial laboratory test at the Gl outpatient department revealed thyroid stimulating hormone $<0.01 \mu \mathrm{lU} / \mathrm{mL}$ and additional blood tests showed elevated thyroid hormones and positive thyroid stimulating hormone receptor antibody. The vomiting and epigastric pain improved remarkably after treatment with antithyroid drugs. Clinicians should consider the possibility of thyrotoxicosis in patient with unexplained and repeated vomiting.

(J Neurogastroenterol Motil 2010;16:428-432)

Key Words

Adolescent; Thyrotoxicosis; Vomiting

\section{Introduction}

Vomiting is one of the most common symptoms in gastroenterology clinics and usually originates from gastrointestinal (GI) disorders. However, various extraintestinal disorders can also cause vomiting. ${ }^{1,2}$

Patients with thyroid disorders may present with a wide range of GI symptoms (eg, diarrhea, frequent defecation, constipation, dyspepsia, nausea, vomiting and abdominal pain). ${ }^{3}$ Some patients with masked thyrotoxicosis who lack the unique clinical feature usually presented as cardiovascular abnormalities such as heart failure, but also occasionally as GI abnormalities including dysphagia, ${ }^{4}$ vomiting ${ }^{5}$ and abdominal pain. ${ }^{6}$ We report a case of an adolescent female with undiagnosed thyrotoxicosis who was initially treated for vomiting under a diagnosis of duodenogastric reflux and reflux esophagitis.

\section{Case Report}

A 13-year-old female patient was referred to the GI outpatient department of our hospital from a pediatric clinic to un-

Received: August 21, 2010 Revised: September 29, 2010 Accepted: October 2, 2010

(c) This is an Open Access article distributed under the terms of the Creative Commons Attribution Non-Commercial License (http://creativecommons. org/licenses/by-nc/3.0) which permits unrestricted non-commercial use, distribution, and reproduction in any medium, provided the original work is properly cited.

*Correspondence: Yong Sung Kim, MD, PhD

Wonkwang Digestive Disease Research Institute, Wonkwang University Hospital, 344-2 Shinyong-dong, Iksan, Jeollabuk-do 570-711, Korea

Tel: +82-63-859-2563, Fax: +82-63-855-2025, E-mail: wms89@hanmail.net

Financial support: This work was supported by Wonkwang University 2009.

Conflicts of interest: None. 
dergo the esophagogastroduodenoscopy for the evaluation of recurrent vomiting that lasted for 8 days. The vomiting usually occurred in the afternoon and was bilious in nature. Although vomiting was not related to food intake, she had avoided eating because of recurrent vomiting. She also complained of nausea, boring epigastric pain and palpitation, but denied diarrhea or melena. She had lost $8 \mathrm{~kg}$ of weight over 4 months, and her weight was $39.4 \mathrm{~kg}$ (10-25 percentile) and height was $156 \mathrm{~cm}$ (50-75 percentile) at presentation. Past history and family history were not remarkable. She was in Tanner stage 4. Menarche occurred 6 months ago, and menstrual cycles were irregular. Physical examination revealed a dehydrated tongue, cachexic and anxious appearance. Her blood pressure was $100 / 80 \mathrm{mmHg}$, pulse rate was $110 / \mathrm{min}$, respiratory rate was $20 / \mathrm{min}$ and body temperature was $36.6^{\circ} \mathrm{C}$. There was no definite enlargement or palpable mass on the anterior neck, eye abnormality or lymphadenopathy. The abdomen was soft with normal bowel sound and there was no direct or rebound tenderness on the abdomen. Electrocardiography showed sinus tachycardia. Plain abdominal X-ray showed nonspecific findings. Because she had weight loss and palpitation with anxiety, thyroid stimulating hormone (TSH) was included in the initial laboratory test. Esophagogastroduodenoscopy at the first visit of GI outpatient department revealed mild mucosal erythema on $\mathrm{Z}$-line and acute erythematous gastritis with large amount of duodenogastric reflux (Fig. 1). Helicobacter pylori rapid urease test was negative. She was prescribed a proton pump inhibitor, prokinetic and mucosal coating agent (sucralfate) on the basis of her endoscopic diagnosis with GI department follow up after 2 weeks. Her vomiting improved during the first 2 days after medication, however, she visited the emergency department (ED) 5 days later
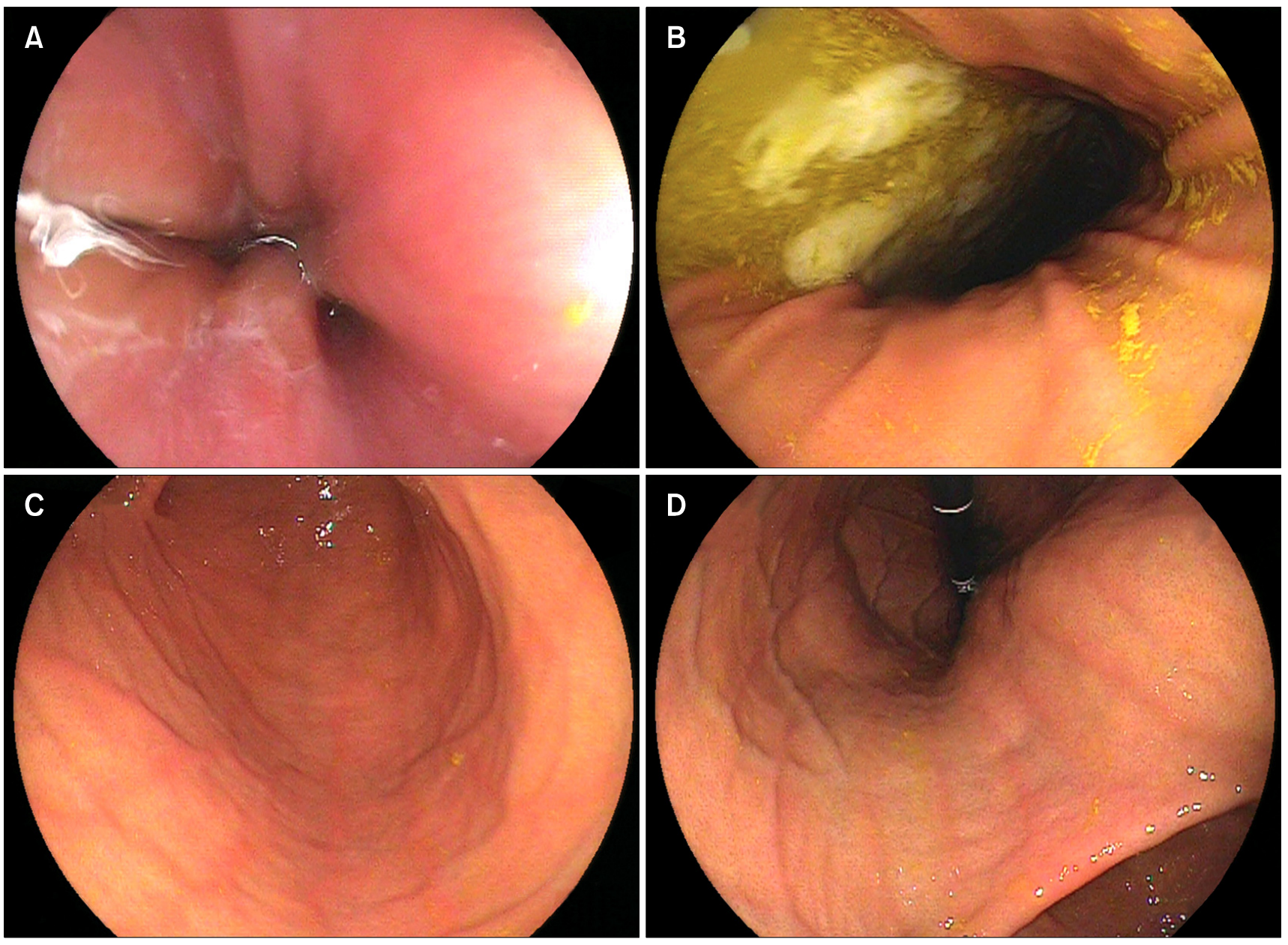

Figure 1. Endoscopic findings show mild erythema with whitish turbidity around Z-line (A) and large amount of bile-mixed fluid in the gastric lumen with bile stainings on the gastric mucosa (B). After suctioning of all fluid and washing the gastric mucosa with water, multiple linear mild erythematous changes on gastric mucosa are observed (C, D). 
because of recurred vomiting and boring epigastric pain. Her blood pressure was $140 / 80 \mathrm{mmHg}$, pulse rate was $88 / \mathrm{min}$, respiratory rate was $20 / \mathrm{min}$ and body temperature was $36.8^{\circ} \mathrm{C}$. Physical examination revealed mild epigastric direct tenderness. The physician of the ED found that she already had blood tests including TSH at GI outpatient department and it revealed TSH $<0.01 \mu \mathrm{IU} / \mathrm{mL}$ (normal range 0.35-5.55 $\mu \mathrm{IU} / \mathrm{mL}$ ). Complete blood count with differential, electrolyte and glucose were within normal limit. A liver function tests showed albumin $4.34 \mathrm{~g} / \mathrm{dL}$ (normal range 3.8-5.3 g/dL), total bilirubin $2.47 \mathrm{mg} / \mathrm{dL}$ (normal range 0.3-1.2 $\mathrm{mg} / \mathrm{dL}$ ), alkaline phosphatase $139 \mathrm{IU} / \mathrm{L}$ (normal range 25-100 IU/L), AST $30 \mathrm{IU} / \mathrm{L}$ (normal range 0-35 IU/L) and ALT 38 IU/L (normal range 0-35 IU/L). A repeated liver function test at $\mathrm{ED}$ showed total bilirubin $1.7 \mathrm{mg} / \mathrm{dL}$, alkaline phosphatase 133 IU/L, AST 30 IU/L, ALT 42 IU/L and magnesium and calcium were within normal limit. Subsequent blood tests for the thyroid showed free triiodothyroxine (T3) $>8.0 \mathrm{ng} /$ $\mathrm{mL}$ (normal range $0.60-1.81 \mathrm{ng} / \mathrm{mL}$ ), free thyroxine $(\mathrm{T} 4)>12.0$ $\mathrm{ng} / \mathrm{dL}$ (normal range 0.89-1.76 ng/dL), TSH receptor antibody
$37.4 \%$ (normal range $\leq 15.0 \%$ ), anti-thyroid microsomal antibody $6.22 \mathrm{U} / \mathrm{mL}$ (normal range $\leq 3.0 \mathrm{U} / \mathrm{mL}$ ) and thyroglobulin antibody $6.91 \mathrm{U} / \mathrm{mL}$ (normal range $\leq 3.0 \mathrm{U} / \mathrm{mL}$ ). Thyroid ultrasonography revealed diffusely enlarged glands, decreased parenchymal echogenecity and increased vascularity of both glands (Fig. 2). Treatment was initiated with propylthiouracil (PTU) $3.75 \mathrm{mg} / \mathrm{kg} /$ day and propranolol $1 \mathrm{mg} / \mathrm{kg} /$ day, after 4 days of treatment, vomiting, epigastric pain and palpitation were improved remarkably. She was discharged with a maintenance dose of PTU $(3.75 \mathrm{mg} / \mathrm{kg} / \mathrm{day})$ without prokinetic or proton pump inhibitor.

She was hospitalized again 5 days later because vomiting had recurred. Liver function tests returned to normal limits, but thyroid function tests were still elevated $(\mathrm{TSH}<0.01 \mu \mathrm{IU} / \mathrm{mL}$, free T3 $6.31 \mathrm{ng} / \mathrm{mL}$ and free T4 $5.09 \mathrm{ng} / \mathrm{dL})$. We switched treatment from PTU to methimazole $0.4 \mathrm{mg} / \mathrm{kg} /$ day and added inorganic iodine (Lugol's solution) for 5 days to prevent thyroid hormone release. After 3 days, there was no further vomiting, and free T3 and free T4 were decreased to $4.46 \mathrm{ng} / \mathrm{mL}$ and 2.24 $\mathrm{ng} / \mathrm{dL}$, respectively. She was discharged with a maintenance dose
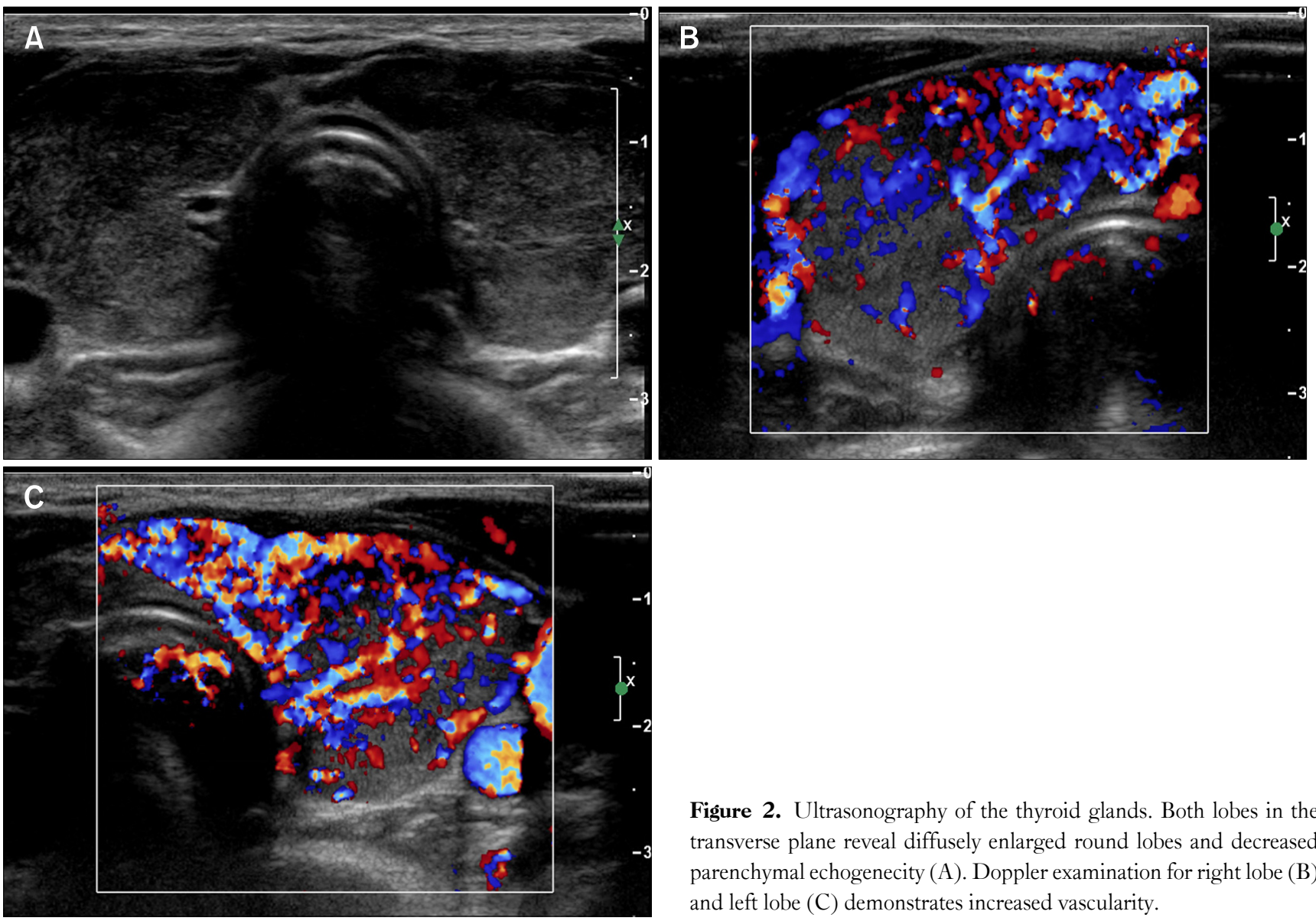

Figure 2. Ultrasonography of the thyroid glands. Both lobes in the transverse plane reveal diffusely enlarged round lobes and decreased parenchymal echogenecity (A). Doppler examination for right lobe (B) and left lobe $(\mathrm{C})$ demonstrates increased vascularity. 
of methimazole ( $0.4 \mathrm{mg} / \mathrm{kg} / \mathrm{day})$ and propranolol $(1 \mathrm{mg} / \mathrm{kg} / \mathrm{day})$.

After 2 months with methimazole and propranolol maintenance therapy, her symptoms were stable and free T4 returned to normal limits $(1.27 \mathrm{ng} / \mathrm{dL})$ despite still having low level of TSH $(<0.01 \mu \mathrm{IU} / \mathrm{mL})$. Over next 16 months with methimazole monotherapy, vomiting has not recurred and she became euthyroid with normalized TSH receptor antibody.

\section{Discussion}

GI symptoms such as hyperphagia, diarrhea, and frequent defecation are commonly associated with thyrotoxicosis, whereas vomiting, abdominal pain, and dysphagia are uncommon. Although vomiting, nausea and abdominal pain have not been generally included as common presenting symptoms for thyrotoxicosis, a review of 25 newly diagnosed thyrotoxicosis cases reported that the significant number of thyrotoxic patients complained of vomiting (44\%), nausea (28\%) and abdominal pain $(20 \%){ }^{7}$ One or more of these abdominal symptoms were included as a chief complaint in $36 \%$ of cases reviewed. ${ }^{7}$

Interestingly, thyrotoxic vomiting can occur intermittently, and unique clinical features of thyrotoxicosis including goiter, ophthalmopathy such as exophthalmos or lid retraction are rarely associated with cases of thyrotoxic vomiting. ${ }^{5,6,8}$ Our patient was diagnosed as hyperthyroidism caused by Graves' disease based on autoantibodies and sonographic finding. She was 13-year-old child and the characteristics of pediatric Graves' disease also make clinician difficult to diagnose thyrotoxicosis. In pediatric Graves' disease, the size of the thyroid gland is highly variable and the goiter may go unnoticed in patients with a slightly enlarged thyroid gland, and ophthalmic abnormalities are less severe in children than in adults. ${ }^{9}$ Therefore, children with undiagnosed thyrotoxicosis may initially be referred to cardiologists with a heart murmur, gastroenterologists with GI symptoms and failure to thrive, or psychiatrist because of challenging behavior and school refusal before being referred to an endocrinologist. ${ }^{10}$

When rare GI symptoms like vomiting present as initial symptoms in patients with thyrotoxicosis and there are no typical features of thyrotoxicosis, it can be misdiagnosed as GI disorders. If the physician is misled to another GI disorder and vomiting is prolonged for several weeks under wrong treatment, this patient not only can progress to a life-threatening situation, but also may have many unnecessary tests under suspicion of functional vomiting or even exploratory laparotomy. ${ }^{1,6,11}$

In cases of thyrotoxicosis that showed only GI symptoms, di- agnostic clues might be chronicity of symptoms, prominent weight loss and tachycardia. ${ }^{6,8,12}$ In our patient, the prominent weight loss over several months, palpitation and anxiety were clues to the suspicion of thyrotoxicosis. However, since these symptoms are not pathognomic signs of thyrotoxicosis and often accompanied by other GI symptoms, proper diagnosis is difficult and delayed considerably.

There are several possible mechanisms by which thyrotoxic vomiting develops. The first proposed mechanism is an increase in $\beta$-adrenergic activity due to an increased number of $\beta$-adrenergic receptors. ${ }^{13}$ There have been several reports of rapid symptomatic improvement after administration of $\beta$-blockers before the normalization of thyroid hormones. ${ }^{6,8,12}$ Based on these reports, it is conceivable that the vomiting in thyrotoxicosis may be attributed to sympathomimetic effects of thyroid hormones as dysrhythmias, fever, tremors, palpitations and anxiety. The rapid symptomatic improvement may reflect the ability of $\beta$-blockers to reduce the peripheral conversion of thyroxine to triiodothyronine. $^{12}$

Second, increased thyroid hormones can cause emesis. There is a reported case that symptoms were not improved by the administration of $\beta$-blockers but improved after thyroid hormone levels normalized. ${ }^{14}$ In our case, clinical symptoms were temporarily improved by the administration of $\beta$-blocker with subsequent recurrence within 5 days and were completely improved after thyroid hormone levels decreased to near normal range by Lugol's solution. The mechanism for vomiting in thyrotoxicosis may be similar to that for vomiting in hyperemesis gravidarum. Increased $\alpha$-subunit of human chorionic gonadotropin induces secretion of thyroxine through a TSH-like activity. ${ }^{15}$ However, it is still controversial whether thyroid hormones themselves act as an emetic factor in thyrotoxic vomiting, although it has been speculated that thyroid hormones stimulate the chemical trigger zone. ${ }^{5}$

Third, thyroid hormones can alter gastric motility and decrease gastric emptying secondary to the malfunction of the pyloric sphincter. A plausible explanation for this phenomenon is that thyroid hormones alter magnesium homeostasis, and hypomagnesemia affect smooth muscle directly or autonomic innervations of the upper GI smooth muscle. ${ }^{16,17}$ The rate of gastric emptying is slightly increased after the restoration of euthyroidism $^{18}$ and postprandial tachygastrias are significantly reduced after antithyroid therapy. ${ }^{19,20}$

Fourth, the estrogen was suggested an emetic cause in thyrotoxicosis because there are female predominance in thyrotoxic vomiting and estrogen level could be increased in patients of both 
sexes with thyrotoxicosis. ${ }^{5,21}$ And then the raised estrogen level may induce nausea and vomiting only in susceptible patients. ${ }^{22}$

Lastly, it was suggested that functional duodenal obstruction in thyrotoxicosis may present much like the obstruction in superior mesenteric artery syndrome. ${ }^{14}$ Possible causes of this obstruction are prominent weight loss, supine position in a patient with prolonged and severe illness and hypermotility induced volvulus of duodenal third portion.

Thyrotoxic vomiting has a excellent prognosis and usually improved within several days after initiation of antithyroid treatment in the majority of reported cases. ${ }^{5-8,12}$ However, since our patient was pediatric Graves' disease, we should consider genetic background of Graves' disease and higher frequency of relapse than adult. ${ }^{9}$

In conclusion, the possibility of atypical thyrotoxicosis should be considered in patients with persistent unexplained vomiting. Since symptomatic improvement is related to the thyroid hormone level, appropriate treatment strategies and meticulous surveillance for the thyroid hormone level are mandatory.

\section{References}

1. Malagelada JR, Camilleri M. Unexplained vomiting: a diagnostic challenge. Ann Intern Med 1984;101:211-218.

2. Metz A, Hebbard G. Nausea and vomiting in adults - a diagnostic approach. Aust Fam Physician 2007;36:688-692.

3. Ebert EC. The thyroid and the gut. J Clin Gastroenterol 2010;44: 402-406

4. Noto H, Mitsuhashi T, Ishibashi S, Kimura S. Hyperthyroidism presenting as dysphagia. Intern Med 2000;39:472-473.

5. Rosenthal FD, Jones C, Lewis SI. Thyrotoxic vomiting. Br Med J 1976;2:209-211.

6. Gharahbaghian L, Brosnan DP, Fox JC, Stratton SJ, Langdorf MI. New onset thyrotoxicosis presenting as vomiting, abdominal pain and transaminitis in the emergency department. West J Emerg Med 2007; 8:97-100.

7. Harper MB. Vomiting, nausea, and abdominal pain: unrecognized symptoms of thyrotoxicosis. J Fam Pract 1989;29:382-386.
8. Hoogendoorn EH, Cools BM. Hyperthyrotoxicosis as a cause of persistent vomiting. Neth J Med 2004;62:293-296.

9. Kaguelidou F, Carel JC, Léger J. Graves' disease in childhood: advances in management with antithyroid drug therapy. Horm Res 2009;71:310-317.

10. Birrell G, Cheetham T. Juvenile thyrotoxicosis; can we do better? Arch Dis Child 2004;89:745-750.

11. Zhao Y, Ke M, Wang Z, et al. Pathophysiological and psychosocial study in patients with functional vomiting. J Neurogastroenterol Motil 2010;16:274-280.

12. Dasari VM, Shatnawei A, Lashner BA, Kirby DF. An uncommon presentation of a common diagnosis: nausea and abdominal pain in thyrotoxicosis. Gastroenterol Hepatol 2009;5:209-211.

13. Bilezikian JP, Loeb JN. The influence of hyperthyroidism and hypothyroidism on $\alpha$ - and $\beta$-adrenergic receptor systems and adrenergic responsiveness. Endocr Rev 1983;4:378-388.

14. Cansler CL, Latham JA, Brown PM Jr, Chapman WH, Magner JA. Duodenal obstruction in thyroid storm. South Med J 1997; 90:1143-1146.

15. Pekary AE, Jackson IM, Goodwin TM, Pang XP, Hein MD, Hershman JM. Increased in vitro thyrotropic activity of partially sialated human chorionic gonadotropin extracted from hydatidiform moles of patients with hyperthyroidism. J Clin Endocrinol Metab 1993;76:70-74.

16. Parkin AJ, Nisbet AP, Bishop N. Vomiting due to gastric stasis as the presenting feature in thyrotoxicosis. Postgrad Med J 1981;57: 405 .

17. Ballard B, Torres LM, Romani A. Effect of thyroid hormone on $\mathrm{Mg}(2+)$ homeostasis and extrusion in cardiac cells. Mol Cell Biochem 2008;318:117-127.

18. Jonderko K, Jonderko G, Marcisz C, Golab T. Gastric emptying in hyperthyroidism. Am J Gastroenterol 1997;92:835-838.

19. Pfaffenbach B, Adamek RJ, Hagelmann D, Schaffstein J, Wegener M. Effect of hyperthyroidism on antral myoelectrical activity, gastric emptying and dyspepsia in man. Hepatogastroenterology 1997;44: 1500-1508.

20. Gunsar F, Yilmaz S, Bor S, et al. Effect of hypo- and hyperthyroidism on gastric myoelectrical activity. Dig Dis Sci 2003;48:706-712.

21. Wang KW, Mui KS. Thyrotoxic hyperemesis: a case report. Singapore Med J 1989;30:493-494.

22. Chopra IJ, Abraham GE, Chopra U, Solomon DH, Odell WD. Alterations in circulating estradiol-17 in male patients with Graves's disease. N Engl J Med 1972;286:124-129. 